\title{
Synthesis of new trichloro(fluoro)methylated biheterocycles
}

\author{
Alynne A. Souto ${ }^{a, \star}$, Alex F. C. Flores ${ }^{a}$, Juliana L. Malavolta ${ }^{a}$, Morgana Doneda $^{a}$ \\ Departamento de Química, Universidade Federal de Santa Maria, Santa Maria, RS, Brasil \\ *alynnealegre@terra.com.br
}

Keywords: heterocycles, hydrazides, pyrazole.

\section{INTRODUCTION}

Among the chemical compounds used in the pharmaceutical and agrochemicals industry, most of them have a heterocyclic ring. Among these, pyrazoles and pyrimidines, which have large importance in the field of medicinal chemistry, stand out being used as anti-inflammatory, antibiotics, analgesics, antibacterial, antineoplastic, among other. ${ }^{1}$

Biheterocycles have two heterocyclic rings connected by an alkyl group, carbonyl derivatives or directly between themselves. Their importance in the chemical industry and pharmaceutical has already been reported, mainly being used as hypoglycemic agents. $^{2}$

Thus, the objectives of this work are the synthesis and reactivity study of hidrazides, pyrimidines and pyrazoles synthesized in our laboratories.

\section{RESULTS AND DISCUSSION}

Compounds 1 and 2, precursors for the synthetic route, are synthesized through the methods described in the literature. ${ }^{3}$

The synthesis of hydrazides 3,4 occurs by the reaction of pyrimidines and pyrazoles 1 and 2 , previously synthesized, with hydrazine hydrate and methanol under reflux for 2 hours. After removing the solvent, the products were obtained in $68 \%$ yield and characterized by ${ }^{1} \mathrm{H}$ NMR spectroscopy, which evidenced the disappearance of the methoxy group for the two cases.

To obtain biheterocycles $\mathbf{5 - 8}$, the hydrazides $\mathbf{3}$ and $\mathbf{4}$ were condensed with different $\beta$ alkoxyvinyltrihalomethyl ketones - whose synthesis is well established in ours laboratories - by refluxing in ethanol for 24 hours (Scheme 1).

The biheterocycle targets were obtained in good yields and high purity and their structures were elucidated by ${ }^{1} \mathrm{H} /{ }^{13} \mathrm{C}$ NMR spectroscopy and CG/MS data.

All synthesized compounds are solids and, when necessary, were recrystallized in hot hexane. The pyrazole compounds synthesized are unpublished and demonstrate the versatility of $\beta$ alkoxyvinyltrihalomethyl ketones produced in our laboratories.

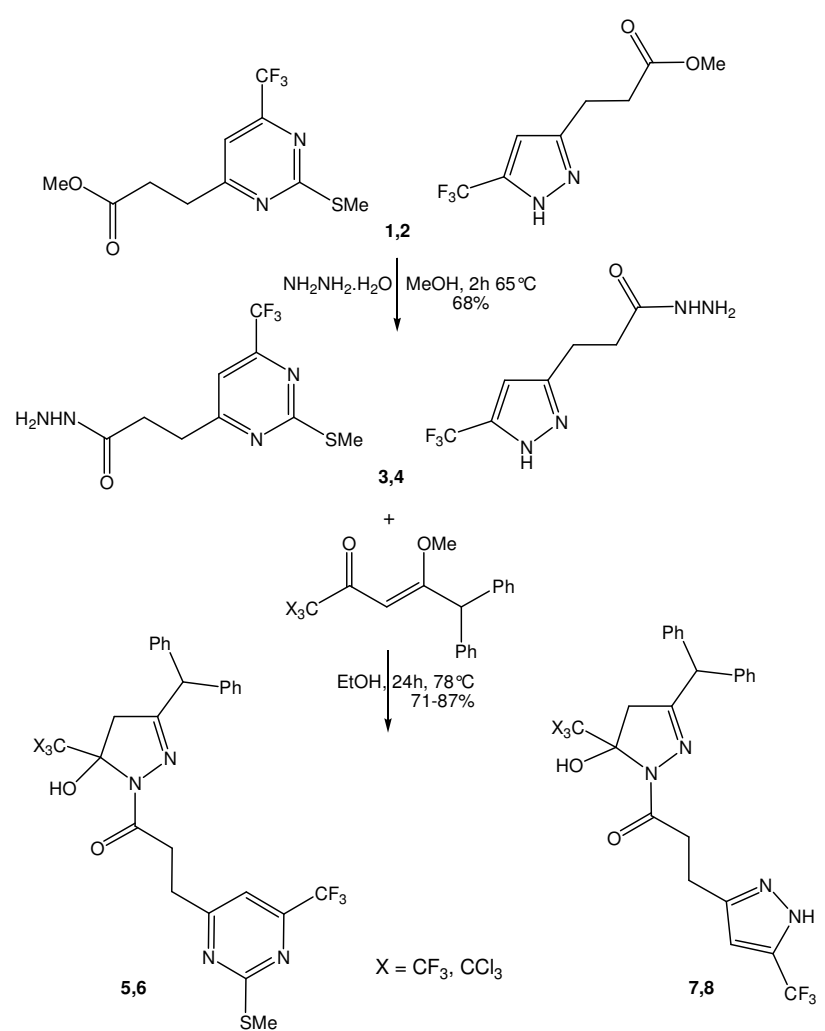

Scheme 1. Synthesis of biheterocycles

\section{CONCLUSION}

The hydrazides $\mathbf{3}$ and $\mathbf{4}$ were obtained by a simple synthetic route from readily available reagents. Their reactivity towards $\beta$-alkoxyvinyltrihalomethyl ketones was tested, obtaining new biheterocyle compounds in good yields. These compounds may have high value to the medicinal chemistry and materials.

\section{ACKNOWLEDGEMENTS}

We are grateful for the financial support from $\mathrm{CNPq}$ (Grant 476158/2007-9), CAPES and FAPERGS.

\section{REFERENCES}

1 Jaiprakash, N. S.; Aniruddha, R. C.; Devanand, B. S., Bioorg. Med. Chem. Lett. 2011, 21, 444

2 (a) Lotti, B.; Vezossi, O.. Farmaco 1972, 24, 313. (b) Soliman,

R.; Darwish, A. S. J. Med. Chem. 1983, 26, 1659. (c) Wright, J. B.; Dulin, W. E.; Markillie, J. H. J. Med. Chem. 1964, 7, 102.

3 (a) Flores, A. F. C.; Pizzuti, L.; Brondani, S.; Rossato, M.; Zanatta, N.; Martins, M. A. P. J. Braz. Chem. Soc. 2007, 18, 1316. (b) Piovesan, L. A. Tese de Doutorado. Universidade Federal de Santa Maria 2009. 